\title{
Liposomes: a new non-pharmacological therapy concept for seasonal-allergic-rhinoconjunctivitis
}

\author{
M. Böhm · G. Avgitidou · E. El Hassan · R. Mösges
}

Received: 15 November 2010 / Accepted: 24 June 2011 / Published online: 15 July 2011

(C) The Author(s) 2011. This article is published with open access at Springerlink.com

\begin{abstract}
Mucosal barrier disorders play an important role in the pathomechanism of the allergic disease. A new approach for their treatment uses liposomes, which consist of phospholipids that make up $75 \%$ of the protective nasal surfactant layer. Our aim was to investigate the efficacy of liposomal-based therapy, as a comprehensive treatment alternative to guideline cromoglycate-based therapy, in the treatment of seasonal allergic rhinoconjunctivitis (SAR). We compared nasal and conjunctival symptom reduction with LipoNasal $n$ nasal spray used as monotherapy (LNM), or LipoNasal $n$ nasal spray and Tears Again eye spray combination therapy (LTC), against standard cromoglycate combination therapy (CGC). This prospective, controlled, open observational study was conducted monocentrically. According to their symptoms and preferences 72 patients with SAR were distributed in three equal groups. The study comprised two visits at an interval of 7 days. The efficacy was examined by daily documenting nasal and conjunctival symptom scores. The Nasal-Spray-Sensory-Scale and the Eye-Drops/Spray-Sensory-Scale were used to investigate the tolerability. Quality of life (QoL) was evaluated, using the RHINASTHMA QoL German adapted version. LNM achieved significant improvement in nasal $(p<0.001)$ and conjunctival symptoms $(p=0.050)$. The symptom reduction using CGC was equally significant. LTC led to significant nasal symptom relief $(p=0.045)$. QoL did not improve significantly in all groups $(p>0.05)$. The tolerability of all treatments was good and no adverse reactions were observed. In all treatment groups the improvement of the
\end{abstract}

M. Böhm · G. Avgitidou · E. El Hassan · R. Mösges ( $\square)$ Institute of Medical Statistics, Informatics and Epidemiology (IMSIE), University of Cologne, 50924 Cologne, Germany e-mail: Ralph@Moesges.DE nasal and conjunctival symptom scores exceeds the minimal clinically important difference (MCID). The results demonstrate good tolerability and efficacy of non-pharmaceutical liposomal-based treatment (LipoNasal $n$ and Tears Again), given as monotherapy or combination therapy, for nasal and conjunctival symptoms caused by SAR. This study indicates that liposomal-based treatment for SAR may be a comparable alternative to cromoglycate therapy. Further studies are needed to verify these findings.

Keywords Seasonal allergic rhinoconjunctivitis . Liposomes · Cromoglycate · Efficacy · Quality of life

\section{Introduction}

A new approach for treating mucosal barrier disorders, which are an important part of the pathomechanism of allergic disease, uses liposomes, which consist of phospholipids that make up $75 \%$ of the protective nasal surfactant layer $[1,2]$. These integrate into damaged cell membranes, protecting upper airways against pathogens [3-5] and thus stabilize respiratory barriers and strengthen their antiinflammatory and wound-healing capacities $[3,6,7]$. A number of recent studies [8-10], practically demonstrate that the symptoms of seasonal allergic rhinitis (SAR) are effectively reduced by nasal application of liposomes, which have been available in the German pharmaceutical market since 2007 [10], on an inflamed nasal mucosa. In the open, mono-centric, prospective study conducted by Weston (2010) [8], LipoNasal, a liposomal nasal spray, led to a significant reduction of SAR symptoms and an improvement of quality of life, comparable to the effect of a standard treatment with an antihistamine/glucocorticosteroid spray. We decided to elaborate this interesting area, and 
assess liposomal-based monotherapy or combination therapy as comprehensive treatment alternatives to the standard guideline therapy for treating conjunctival and nasal symptoms experienced in SAR. We compared the efficacy and tolerability of a cromoglycate-based combination therapy (Cromoglycate) specified by guidelines against a liposomal nasal spray (LipoNasal $n$ ), alone or combined with Tears Again eye spray, in an open, monocentric, prospective study. The present study was carried out according to good clinical practice. As both the monotherapy and combination therapies are in accordance with the labelling the approval by an ethics committee was not mandatory. Nevertheless, the responsible ethics committee was consulted with respect to professional regulations.

\section{Materials and methods}

Study design

The study, conducted from July to August 2009, was an open-label, prospective, controlled, observational study with 72 patients aged 18-69 years, with SAR, triggered by grass, crop and/or herbal pollens, diagnosed by skin-prick test. The study had a treatment and observation period of 1 week per patient, with two visits to the study centre at day 0 (Round 1) and day 7 (Round 2).

Patient allocation and medication

According to the observational study design an approved consent was taken from each patient. Those patients that gave their informed consent prior to their inclusion in the study were allocated by the principal investigator into three treatment groups, 24 patients in each group, treated with either of two combination therapies or one monotherapy, depending on their symptoms, preference and the expected compliance. Patients, suffering from late pollen-induced SAR, were first offered a standard therapy combination based on guideline (1) cromoglycate combination therapy (CGC) with cromoglycate eye drops and nasal spray.

Those patients having reservations towards pharmacological therapy were alternatively offered medicinal products based on liposomal suspensions, choosing between (2) LipoNasal $n$ nasal spray and Tears Again eye spray combination therapy (LTC) (3) LipoNasal $n$ nasal spray as monotherapy (LNM).

Tears Again is a liposomal spray to be applied on the closed eyelids and originally is not designed for treatment of allergies. Its intended use is to stabilize the tear film lipid layer in case of a tear film deficiency, which is associated, e.g., with allergic conjunctivitis, so that it may provide relieve of symptoms by stabilization of the natural tear film system.
LipoNasal $n$ (LipoNasal new) hay fever spray, a new formulation with a reduced menthol fraction $(0.004 \%)$, and Tears Again eye spray are products of "Optima Pharmazeutische GmbH, Moosburg". The liposomes consist of highly purified soya lecithin, which contains at least $94 \%$ phosphatidylcholine and other phospholipids. Medication was applied according to the package instructions. Patients applied LipoNasal n 2-3 times/nare/day (0.4-0.6 ml of liposome suspension/day) and Tears Again 2-3 times/eye/day.

The active ingredient of CGC (HEXAL AG, Holzkirchen, Germany), is sodium cromoglycate. Its daily dose is $11.2-16.8 \mathrm{mg}(0.56-0.84 \mathrm{ml})$ or 3-4 sprays/nostril/day and $4-8 \mathrm{mg}(0.2-0.4 \mathrm{ml})$ or 2-4 drops/eye/day.

During the whole observation period patients were advised by the investigator not to use any other form of drugs, e.g., oral antihistamines for treating their symptoms of SAR.

\section{Outcome parameters}

The patients' demographic data were collected on day 0 . The daily allergen exposure was determined by means of the weather score (mean of single scores "sunny" 1 , "cloudy" 0.5 and/or "rainy" 0) and whether patients were able to stay outside during the day or sleep with an open window during the night, as described in Weston et al. [8]. A record of the number of sprays/nare/day or drops or sprays/eye/day, was kept, reflecting the compliance of the patients.

After application of the particular medication, the duration till the onset of action was noted by the patients $(<5,5$ $10,10-30,30-60 \mathrm{~min}, 1-2,2-4,4-8$, no onset of action).

To assess efficacy, patients daily rated their nasal (rhinorrhea, blocked nose, sneezing, itching) and conjunctival (redness, itching, tearing) symptoms on a discrete ordinal scale ( 0 no, 1 mild, 2 moderate, 3 severe symptoms). Values were added up into the total nasal symptom score (NSS) and conjunctival symptom score (CSS), respectively, which were in turn summed into the global rhinoconjunctival-score (RCSS). To further evaluate the efficacy objectively, the principal investigator conducted a rhinoscopy at visits 1 and 2 and scored the rinorrhea, redness and oedema on the rhinoscopic score ( 0 no, 1 mild, 2 severe). Redness was evaluated by the investigator who used a colour-calibrated video endoscope and recorded the images. No decongestants were used for assessment of oedema as they may have interfered with the evaluation of the parameter blocked nose.

The Nasal-Spray-Sensory-Scale [11] and the Eye-Drops/ Spray-Sensory-Scale were used to investigate the tolerability of the medications by asking questions about the sensation perceived by patients immediately and $2 \mathrm{~min}$ after application, done by marking a Visual Analogue Scale 
(VAS) (0 worst evaluation, 100 best evaluation). This was compared at visits 1 and 2, looking for improved tolerability and decreased negative sensations.

The safety was assessed through precise documentation of the side effects.

Using the by Mösges et al. validated German Adapted Version (GAV) of the RHINASTHMA-quality-of-lifescale $[12,13]$ the therapy's impact on QoL could be captured, by assessing 42 major symptoms and problems of SAR before and after treatment on a 4-point-scale (where 0 insignificant, and 3 very significant). Additionally, patients evaluated their daily subjective state of health and quality of sleep (Visual Analogue Scale: 0 very bad, 100 very good).

\section{Statistical methods}

Statistical analysis was conducted using SPSS 18 for Windows. Data were entered twice to reduce data entry errors and check for plausibility. Unavailable data were treated as "missing values" or substituted by the "last value carried forward" method for calculating the area under the curve (AUC).

To quantitatively describe the main study population features, descriptive statistics were used. After checking for normal distribution using the Kolmogorov-Smirnov test, the differences for paired and unpaired variables not normally distributed were tested for significance using the Wilcoxon and Kruskal-Wallis test, respectively, with significance defined at $p<0.05$.

\section{Results}

Homogeneity of treated groups

In total, 33 women and 39 men aged 18-69 years (mean $=39.5$ years) were divided into three treatment groups, which had statistically homogenous demographic data (Table 1), allergy diagnoses (SAR, PAR, Asthma, mono- or poly-allergy) (Table 2), symptom scores, allergen exposure, compliance and life quality at the beginning of the study (Table 3). During the assessment period none of the patients under observation used any other topic or systemic anti-allergy medication.

Onset of action

A fast onset of action was noticed after nasal sprays application in all groups. Within the first hour, $70.8 \%$ of the CGC group, $66.7 \%$ of the LTC group and $91.7 \%$ of the LNM-treated patients felt the effect onset. Moreover, within 5 min of application, $12.5 \%$ of the CGC group, $16.7 \%$ of
Table 1 Demographic data

\begin{tabular}{llll}
\hline & LNM & LTC & CGC \\
\hline Number of patients & 24 & 24 & 24 \\
Sex (male/female) & $14 / 10$ & $13 / 11$ & $12 / 12$ \\
Mean age (years) & $39 \pm 9.1$ & $40 \pm 16.3$ & $40 \pm 15.3$ \\
Mean height $(\mathrm{cm})$ & $177 \pm 9$ & $176 \pm 10$ & $174 \pm 9$ \\
Mean weight $(\mathrm{kg})$ & $86 \pm 17.63$ & $80 \pm 16.55$ & $79.9 \pm 17.79$ \\
\hline
\end{tabular}

Table 2 Allergy diagnoses

\begin{tabular}{llll}
\hline & LNM & LTC & CGC \\
\hline Number of patients & 24 & 24 & 24 \\
SAR (number/\%) & $24 / 100.0$ & $24 / 100.0$ & $24 / 100.0$ \\
PAR (number/\%) & $8 / 33.3$ & $4 / 16.6$ & $7 / 29.2$ \\
Asthma (number/\%) & $4 / 16.7$ & $2 / 8.3$ & $1 / 4.2$ \\
Mono-allergy & 16 & 20 & 17 \\
Poly-allergy & 8 & 4 & 7 \\
\hline
\end{tabular}

Table 3 Comparison of symptom scores and quality of life at inclusion (Kruskal-Wallis test)

\begin{tabular}{ll}
\hline & $p$ values \\
\hline Nasal score & 0.051 \\
Conjunctival score & 0.760 \\
Rhinoconjunctival & 0.427 \\
$\quad$ score & \\
Rhinoscopic score & 0.055 \\
Quality of life & 0.172 \\
\hline
\end{tabular}

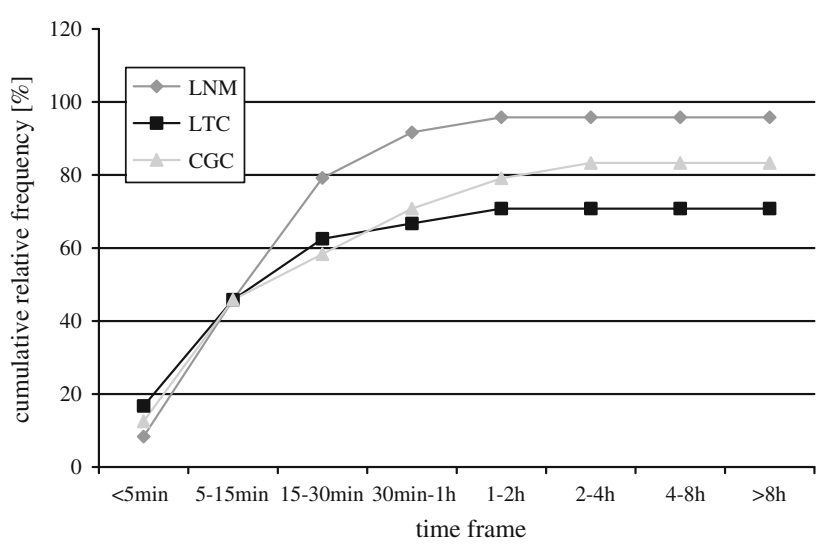

Fig. 1 Development of the onset of action of the nasal sprays

the LTC group and $8.3 \%$ of the LNM group felt the medication taking effect. In all groups, $45.8 \%$ of the patients felt the action onset after 5-15 min (Fig. 1).

For the Tears Again drops, 37.5\%, and with Cromoglycate drops, $66.7 \%$ of the patients noticed an onset of action 


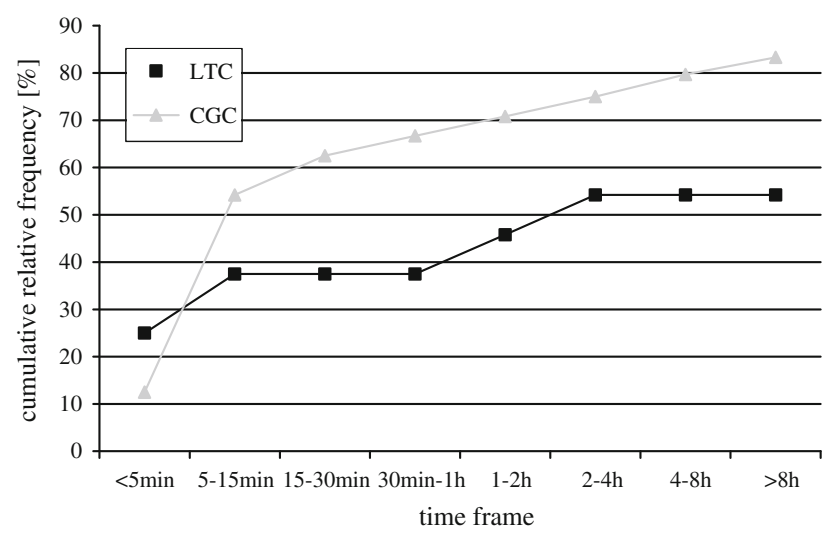

Fig. 2 Development of the onset of action of eye spray/drops

within the first hour after application. However, $25 \%$ of Tears Again users and $12.5 \%$ of Cromoglycate eye drops users felt an onset of action within 5 min (Fig. 2).

\section{Efficacy}

Treatment with LNM achieved significant improvement of the NSS $(p<0.001)$ and CSS $(p=0.05)$ and the RCSS was resultantly significantly reduced from 8.54 to 5.83 $(p=0.01)$ (Table 4$)$. Similarly, CGC therapy significantly reduced both the NSS $(p=0.005)$ and CSS $(p=0.002)$ and hence the RCSS from 7.88 to 4.83 ( $p=0.001$ ), (Fig. 2). On the other hand, LTC therapy significantly improved only the NSS $(p=0.045)$, leading to insignificant reduction of the RCSS from 7.00 to $5.57(p=0.064)$. All nasal sprays lead to rapid symptom reduction within 2 days, after which the RCSS for all treatment groups oscillated around 5.0 (Fig. 3).

To compare symptom reduction between groups, the weekly NSS, CSS and RCSS were baseline-adjusted and the AUC calculated. The resultant improvement in the global RCSS $(p=0.781)$, NSS $(p=0.607)$ and CSS $(p=0.748)$ was similar for all groups. Symptom reduction

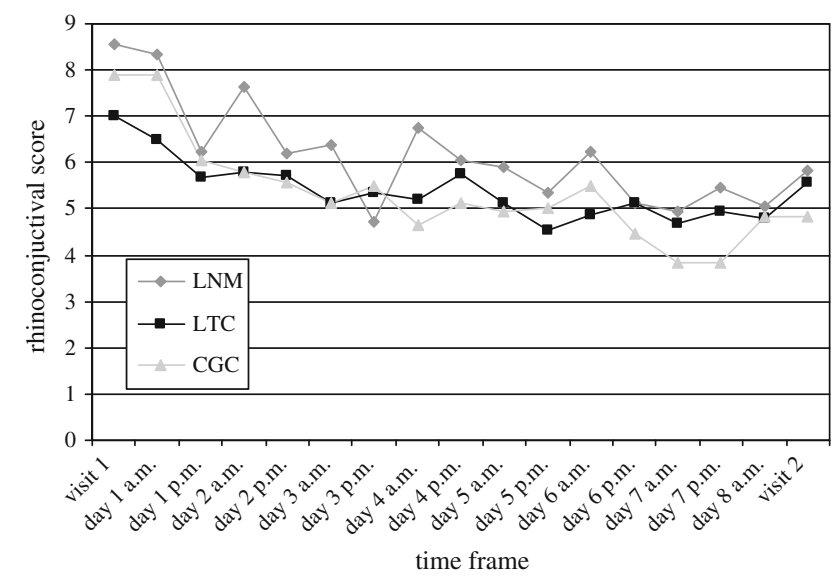

Fig. 3 Development of the rhinoconjunctival score

Table 5 Comparison of the symptom reduction between all groups (Kruskal-Wallis test)

\begin{tabular}{lc}
\hline & $p$ values \\
\hline $\begin{array}{l}\text { AUC baseline-adjusted course of the nasal } \\
\text { symptom score }\end{array}$ & 0.607 \\
$\begin{array}{l}\text { AUC baseline-adjusted course of the conjuncitval } \\
\text { symptom score }\end{array}$ & 0.748 \\
$\begin{array}{l}\text { AUC baseline-adjusted course of the rhinoconjunctival } \\
\text { symptom score }\end{array}$ & 0.781 \\
\hline
\end{tabular}

with liposomal monotherapy and combination therapy was equal to conventional Cromoglycate treatment ( $p>0.05$; Table 5). The efficacy of LNM and CGC therapy is confirmed through the significant reduction of the rhinoscopic scores (LNM, $p=0.010$; CGC, $p=0.001$ ), which was insignificantly reduced with LTC therapy $(p=0.541)$.

In order to ease interpretation of the results and to be confident that the changes in practice will be of perceptible benefit to the patient, the distribution-based minimal clinically

Table 4 Efficacy of symptom reduction (Wilcoxon test)

\begin{tabular}{|c|c|c|c|c|c|c|}
\hline & \multicolumn{2}{|l|}{ LNM } & \multicolumn{2}{|l|}{ LTC } & \multicolumn{2}{|l|}{ CGC } \\
\hline & Symptom score & $p$ values & Symptom score & $p$ values & Symptom score & $p$ values \\
\hline Nasal score day 0 & $6.08 \pm 2.205$ & $<0.001$ & $4.38 \pm 2.223$ & 0.045 & $5.21 \pm 2.021$ & 0.005 \\
\hline Nasal score day 7 & $4.13 \pm 1.985$ & & $3.48 \pm 1.928$ & & $3.50 \pm 2.246$ & \\
\hline Conjunctival score day 0 & $2.46 \pm 1.911$ & 0.050 & $2.63 \pm 1.498$ & 0.167 & $2.67 \pm 1.659$ & 0.002 \\
\hline Conjunctival score day 7 & $1.71 \pm 1.459$ & & $2.09 \pm 1.379$ & & $1.33 \pm 1.049$ & \\
\hline Rhinoconjunctival score day 0 & $8.54 \pm 3.945$ & $<0.001$ & $7.00 \pm 3.217$ & 0.064 & $7.88 \pm 3.392$ & 0.001 \\
\hline Rhinoconjunctival score day 7 & $5.83 \pm 2.973$ & & $5.57 \pm 2.694$ & & $4.83 \pm 2.884$ & \\
\hline Rhinoscopic score day 0 & $4.08 \pm 1.213$ & 0.010 & $3.38 \pm 0.824$ & 0.541 & $3.92 \pm 1.060$ & 0.001 \\
\hline Rhinoscopic score day 7 & $3.25 \pm 1.073$ & & $3.26 \pm 1.176$ & & $2.75 \pm 1.189$ & \\
\hline
\end{tabular}


Table 6 Comparison of the changes in symptom scores during the observation period to the MCID

\begin{tabular}{llll}
\hline & LNM & LTC & CGC \\
\hline $\mathrm{NSS}$ & & & \\
$\mathrm{AMb}$ & -1.72 & -1.09 & -1.58 \\
$\mathrm{bSD}$ & \pm 2.205 & \pm 2.223 & \pm 2.021 \\
$\mathrm{MCID}$ & \pm 0.44 & \pm 0.44 & \pm 0.40 \\
$\mathrm{CSS}$ & & & \\
$\mathrm{AMb}$ & -0.73 & -0.68 & -1.01 \\
$\mathrm{bSD}$ & \pm 1.911 & \pm 1.498 & \pm 1.659 \\
$\mathrm{MCID}$ & \pm 0.38 & \pm 0.30 & \pm 0.33 \\
$\mathrm{RCSS}$ & & & \\
$\mathrm{AMb}$ & -2.45 & -1.77 & -2.60 \\
$\mathrm{bSD}$ & \pm 3.845 & \pm 3.217 & \pm 3.392 \\
$\mathrm{MCID}$ & \pm 0.77 & \pm 0.64 & \pm 0.68 \\
\hline
\end{tabular}

$A M b$ arithmetic mean baseline-adjusted (day 0-7), $b S D$ baseline standard deviation, MCID minimal clinically important difference $(\mathrm{MCID}=$ baseline $\mathrm{SD} \times 0.2)$

important difference $(\mathrm{MCID}=$ baseline $\mathrm{SD} \times 0.2)$ and the arithmetic mean (AM) of the baseline-adjusted symptom scores were calculated (Table 6) $[14,15]$.

Tolerability and safety

The analysis of the nasal-spray-sensory questionnaire showed for LipoNasal $n$ that the smell and taste were found significantly inferior compared with the Cromoglycate nasal spray $(p=<0.001)$ at the beginning of the study week. In contrast, errhine ( $p=0.129)$, irritation 2 min after application $(p=0.251)$ and the amount of drug $(p=0.221)$, reaching the nose and fauces was equal for all nasal sprays (Table 7).

The nasal-spray-sensory questionnaire was re-evaluated on visit 2 to assess for adaptation to the sprays' smell and taste. This showed that LipoNasal $n$ as monotherapy had significantly better tolerated smell intensity $(p=0.043)$; and as combination therapy, a significantly less bitter taste $(p=0.042)$ and irritation $(p=0.046)$ and more drug distribution after $2 \min (p=0.020)$. With Cromoglycate nasal spray, patients did not find any significant difference.
Table 8 Four of 14 items of the eye-spray/drops-sensory-scale on visit $1 ; p$ values calculated by Wilcoxon test

\begin{tabular}{llll}
\hline & LTC & CGC & $p$ values \\
\hline Overall impression & $57 \pm 20.4$ & $75 \pm 21.9$ & 0.004 \\
Adverse effect of vision & $83 \pm 18.0$ & $70 \pm 21.6$ & 0.635 \\
$\begin{array}{l}\text { Irritation of the eye (burning, } \\
\text { irritation) }\end{array}$ & $80 \pm 24.0$ & $74 \pm 25.6$ & 0.192 \\
$\begin{array}{c}\text { Amount of drug, which } \\
\text { reaches nose and fauces }\end{array}$ & $95 \pm 9.9$ & $84 \pm 25.4$ & 0.088 \\
\hline
\end{tabular}

The analysis of the eye-pray/drops-sensory-scale at visit 1 illustrated for Cromoglycate eye drops better initial results for eye moisturization, overall impression, and overall impression $2 \mathrm{~min}$ after application. Tears Again eye spray received a better evaluation for the other six items, like adverse effect on vision and eye irritation (Table 8). Patients treated with Tears Again recognized a stronger visual blurring ( $p=0.036$ ) on visit 2 , in contrast to Cromoglycate eye drop users, who felt less eye irritation $(p=0.005)$.

All treatments were safe and no adverse reactions were observed during the treatment period.

Quality of life

After within-group (Table 9; $p>0.05$ ) and inter-comparison (Table $10 ; p=0.196$ ) of all treatment groups, it was found that the global score of the RHINASTHMA qualityof-life scale did not improve significantly. The subjective feeling improved in all groups; this was significant only for the LNM $(p=0.005)$ and CGC groups $(p=0.004)$. The quality of sleep did improve significantly in the LNM group $(p=0.05)$, but not in the LTC $(p=0.236)$ and CGC $(p=0.284)$ groups.

\section{Discussion}

Treatment with liposomes: a possible therapy concept

The World Health Organisation's Allergic rhinitis and its impact on asthma (ARIA) guidelines provide a progressive
Table 7 Four of 14 items of the nasal-spray-sensory-scale on visit $1 ; p$ values calculated by Kruskal-Wallis test

\begin{tabular}{llllr}
\hline & LNM & LTC & CGC & $p$ values \\
\hline Intensity of aroma & $44 \pm 30.6$ & $36 \pm 22.9$ & $84 \pm 19.9$ & $<0.001$ \\
Errhine & $84 \pm 25.7$ & $77 \pm 21.8$ & $83 \pm 20.9$ & 0.129 \\
$\begin{array}{l}\text { Irritation (burning, irritation) } \\
\quad(2 \text { min after application) }\end{array}$ & $81 \pm 20.9$ & $74 \pm 26.5$ & $85 \pm 20.8$ & 0.251 \\
$\begin{array}{l}\text { Amount of drug, which } \\
\quad \text { reaches nose and fauces }\end{array}$ & $67 \pm 23.7$ & $61 \pm 20.7$ & $71 \pm 28.4$ & 0.221 \\
\hline
\end{tabular}


Table 9 Global score of RHINASTHMA-quality of life scale; $p$ values calculated by Wilcoxon test

\begin{tabular}{|c|c|c|c|c|c|c|}
\hline & \multicolumn{2}{|l|}{ LNM } & \multicolumn{2}{|l|}{ LTC } & \multicolumn{2}{|l|}{ CGC } \\
\hline & Symptom score & $p$ values & Symptom score & $p$ values & Symptom score & $p$ values \\
\hline RHINASTHMA global score visit 1 & $1.56 \pm 0.444$ & 0.130 & $1.80 \pm 0.305$ & 0.082 & $1.76 \pm 0.440$ & 0.082 \\
\hline RHINASTHMA global score visit 2 & $1.66 \pm 0.469$ & & $1.89 \pm 0.393$ & & $1.75 \pm 0.465$ & \\
\hline
\end{tabular}

Table 10 Comparison of the RHINASTHMA global score on visit one and two for all groups (Mann-Whitney $U$ test)

\begin{tabular}{ll}
\hline & $p$ values \\
\hline Visit 1 & 0.172 \\
Visit 2 & 0.196 \\
\hline
\end{tabular}

algorithm for SAR treatment recommending systemic or topical antihistaminics or glucocorticoides with cromones as an alternative and then if necessary, leukotriene antagonists and decongestants [16].

Kaschke [17] published that $64 \%$ of SAR patients have 'cortisone phobia' and only $31 \%$ apply long-term topical steroid treatment, preferring alternative treatments because of negative experiences with steroids [18]. Some patients may have reservations towards using chemical preparations. Liposomes are thus promising, non-chemical, nonsteroid alternatives.

An explanation for liposome mechanism of action assumes that they stabilize the nasal mucosal barrier and treat its dysfunction by integrating in the damaged cell membrane [19] so that fewer allergens can pass through. Andersson [9] assumes that liposomes absorb and thus inactivate allergens [20].

According to the experiences of some patients, liposomal eye sprays used for dry eye can also reduce SAR symptoms. The anti-inflammatory effect was also observed in earlier studies, in which eyelid inflammations in dry eye healed strikingly fast, which was explained through the antioxidatant effect of phosphatidylcholin [21].

\section{Efficacy}

Nasal symptom scores at baseline were numerically different between the three groups and this difference came close to statistical significance with a $p$ value of 0.051 . With regard to the different symptom levels in the groups, "moderate" for LNM, "mild-moderate" for CGC and "mild" for LTC it is not feasible to assess the relative improvement in $\%$ compared with baseline.

For an efficacy claim in allergic rhinoconjunctivitis the EMEA demands that the efficacy for the nasal and eyesymptom-score is discussed separately, e.g., as the symptom-score is a composite scale. Moreover, the overall effect should be balanced so that, e.g., the overall outcome is not driven by a large effect on a limited number of items and no effect or even worsening in the other items of the scale. Also the symptom reduction should be expressed with regard to the minimal clinically change for the outcome parameter [22]. As recommended by Cohen [15], any change over and above an arbitrary limit of 0.2 times the baseline standard deviation (SD) can be interpreted as clinically meaningful (minimum clinically important difference MCID). In all treatment groups the improvement exceeds the MCID so that the assumption of efficacy can be maintained (Table 6). As recommended by Barnes [14], comparing the individual changes from baseline in the NSS during the entire observation period of all groups to a MCID of 0.55 units also provides a clinically meaningful change for all patients.

\section{Onset of action}

The rapid effect onset achieved within an hour with all three therapy options was not surprising, considering it was recorded in $2 / 3$ of patients in earlier studies [10,23].

Tolerability and safety

It was found that patients habituate to the intensity of the smell of the liposomal nasal spray and tolerated it significantly better at visit 2 , possibly due to the smaller menthol fraction. Nevertheless, this smaller menthol fraction may have contributed to the favourable effect on nasal blockage. Both the Cromoglycate and LipoNasal $n$ were well tolerated, which is important to improve compliance and successfully reduce symptoms. No adverse reactions were observed at all.

Quality of life

None of the treatment options caused a significant improvement of the quality of life, possibly because allergen exposure during the study duration reached almost $80 \%$ of the total exposure possible. Also other studies [24] investigating guideline accordant drugs with a proven efficacy, e.g., the second-generation anithistamine Loratadine, demonstrate no improved QoL score after drug administration. Nevertheless, the subjective feeling of patients improved, underlining the effective symptom reduction of all treatment options. 


\section{Conclusion}

It is evident from this study that the prescription-free liposomal-based sprays, given as monotherapy or combination therapy, provide new treatment options for both NSS and conjunctival symptoms caused by SAR. Their efficacy, onset of action and tolerability do not differ significantly from cromoglycate combination therapy, which is known to be an evidence-based, however, weakly effective allergy medication. In all three groups the improvement of the NSS and CSSs exceeds the MCID. The new formulation, with decreased menthol content, provides patients suffering from SAR with a more tolerable liposomal nasal spray.

To sum up, the non-pharmaceutical alternative of liposomes has an appreciable potential to reduce SAR symptoms comparable to the established cromoglycate combination therapy. Thus, patients with reservations concerning pharmaceutical treatment can be treated effectively with liposomes for SAR. Further research is needed to reveal the mechanism of action of liposomes in SAR.

Conflict of interest The authors declare that no conflict of interest exists. The present publication has been prepared under no influence by the manufacturer in the context of a university research project. It was financed using an unrestricted research grant provided by the manufacturer Optima Pharmazeutische GmbH.

Open Access This article is distributed under the terms of the Creative Commons Attribution Noncommercial License which permits any noncommercial use, distribution, and reproduction in any medium, provided the original author(s) and source are credited.

\section{References}

1. Sayed R, Abou-Elhamd K, Abdel-Kader M, Saleem T (2006) Study of surfactant level in cases of primary atrophic rhinitis. J Laryngol Otol 114(04):254-259

2. Yarosh D (1990) Topical application of liposomes. J Photochem Photobiol B, Biol 6(4):445

3. Homann H, Rosbach O, Moll W, Vogt P, Germann G, Hopp M, Langer-Brauburger B, Reimer K, Steinau H (2007) A liposome hydrogel with polyvinyl-pyrrolidone iodine in the local treatment of partial-thickness burn wounds. Ann Plast Surg 59(4):423

4. Khaw BA, Torchilin VP, Vural I, Narula J (1995) Plug and seal: prevention of hypoxic cardiocyte death by sealing membrane lesions with antimyosin-liposomes. Nat Med 1(11):1195-1198

5. Reimer K, Vogt P, Broegmann B, Hauser J, Rossbach O, Kramer A, Rudolph P, Bosse B, Schreier H, Fleischer W (2000) An innovative topical drug formulation for wound healing and infection treatment: in vitro and in vivo investigations of a povidone-iodine liposome hydrogel. Dermatology 201(3):235-241

6. Kanmaz T, Karakayali H, Sakallioglu A, Ozdemir B, Haberal M (2004) Polyunsaturated phosphatidylcholine protects against wound contraction in experimental skin burn injury. J Invest Surg 17(1):15-22

7. Kornilova Z, Selishcheva A, Perel'man M (2001) Effect of phosphatidylcholine liposome on regeneration of surgical wound in guinea pig lung. Bull Exp Biol Med 131(2):191-194
8. Weston LA, Mösges R (2010) Treating seasonal allergic rhinoconjunctivitis with a liposomal nasal spray. Allergologie 33(5):196204

9. Andersson M, Greiff L, Wollmer P (2008) Nasal treatment with a microemulsion reduces allergen challenge-induced symptoms and signs of allergic rhinitis. Acta Otolaryngol 128(6):666-669. doi:10.1080/00016480701642197

10. Meyer-Gutknecht H, Mösges R (2008) Wirkungen eines neuartigen liposomalen Nasensprays auf die Symptome der saisonalen allergischen Rhinitis. HNO kompakt Supplement 1:1-5

11. Mösges R, Pasch N, Sayar A, Schmalz P, Vent J (2009) Survey of Sensory Perception and Patients' Subjective Assessment of the Application of Nasal Sprays-The Nasal-Spray-Sensoric-Scale (Erhebung der sensorischen Wahrnehmung und subjektiven Patienteneinschätzung bei der Verabreichung von Nasenspray-Die Nasen-Spray-Sensorik-Skala). Laryngo, Rhino, Otologie 88 (09):587-591

12. Baiardini I, Pasquali M, Giardini A, Specchia C, Passalacqua G, Venturi S, Braido F, Bonini S, Majani G, Canonica GW (2003) Rhinasthma: a new specific QoL questionnaire for patients with rhinitis and asthma. Allergy 58(4):289-294

13. Mosges R, Schmalz P, Koberlein J, Kaciran M, Baiardini I (2007) The RHINASTHMA-Quality of Life Scale German Adapted Version: validation of a new disease specific quality of life scale for patients suffering from allergic rhinitis and bronchial hyperreactivity. HNO 55(5):357-364. doi:10.1007/s00106-006-1453-0

14. Barnes ML, Vaidyanathan S, Williamson PA, Lipworth BJ (2010) The minimal clinically important difference in allergic rhinitis. Clin Exp Allergy 40(2):242-250. doi:10.1111/j.1365-2222.2009. 03381.x

15. Cohen J (1998) Statistical power analysis for the behavioral science. Lawrence Erlbaum Associates, Hillsdale

16. Bousquet J, Khaltaev N, Cruz AA, Denburg J, Fokkens WJ, Togias A, Zuberbier T, Baena-Cagnani CE, Canonica GW, van Weel C, Agache I, Ait-Khaled N, Bachert C, Blaiss MS, Bonini S, Boulet LP, Bousquet PJ, Camargos P, Carlsen KH, Chen Y, Custovic A, Dahl R, Demoly P, Douagui H, Durham SR, van Wijk RG, Kalayci O, Kaliner MA, Kim YY, Kowalski ML, Kuna P, Le LT, Lemiere C, Li J, Lockey RF, Mavale-Manuel S, Meltzer EO, Mohammad Y, Mullol J, Naclerio R, O'Hehir RE, Ohta K, Ouedraogo S, Palkonen S, Papadopoulos N, Passalacqua G, Pawankar R, Popov TA, Rabe KF, Rosado-Pinto J, Scadding GK, Simons FE, Toskala E, Valovirta E, van Cauwenberge P, Wang DY, Wickman M, Yawn BP, Yorgancioglu A, Yusuf OM, Zar H, Annesi-Maesano I, Bateman ED, Ben Kheder A, Boakye DA, Bouchard J, Burney P, Busse WW, Chan-Yeung M, Chavannes NH, Chuchalin A, Dolen WK, Emuzyte R, Grouse L, Humbert M, Jackson C, Johnston SL, Keith PK, Kemp JP, Klossek JM, Larenas-Linnemann D, Lipworth B, Malo JL, Marshall GD, Naspitz C, Nekam K, Niggemann B, Nizankowska-Mogilnicka E, Okamoto Y, Orru MP, Potter P, Price D, Stoloff SW, Vandenplas O, Viegi G, Williams D (2008) Allergic Rhinitis and its Impact on Asthma (ARIA) 2008 update (in collaboration with the World Health Organization, GA(2)LEN and AllerGen). Allergy 63(Suppl 86):8160. doi:10.1111/j.1398-9995.2007.01620.x

17. Kaschke O (2008) Auswirkungen einer Steroidphobie in Deutschland auf die Therapie mit topischen Glukokortikoiden. MedReport 32(17): 10

18. Passalacqua G, Bousquet PJ, Carlsen KH, Kemp J, Lockey RF, Niggemann B, Pawankar R, Price D, Bousquet J (2006) ARIA update: I-systematic review of complementary and alternative medicine for rhinitis and asthma. J Allergy Clin Immunol 117(5):1054-1062. doi:10.1016/j.jaci.2005.12.1308

19. Schmid MH, Korting HC (1993) Liposomes for atopic dry skin: the rationale for a promising approach. Clin Investig 71(8):649653 
20. Bufe A (2000) A simple advice for the prevention of polleninduced allergic rhinitis. Int Arch Allergy Immunol 121(1):85-86

21. Lee S, Dausch S, Maierhofer G, Dausch D (2004) Ein neues Therapiekonzept zur Behandlung des Trockenen Auges-die Verwendung von Phospholipid-Liposomen A New Therapy Concept with a Liposome Eye Spray for the Treatment of the "Dry Eye". Klin Monatsbl Augenheilkd 221:825-836

22. Committee for Medicinal Products for Human Use (CHMP) and Efficacy Working Party (EWP) (2004) Guideline on the clinical development of medicinal products for the treatment of allergic rhino-conjunctivitis. CHMP/EWP/2455/02
23. Kremer B, Tundermann A, Goldschmidt O (1998) Onset of action, effectiveness and tolerance of levocabastine and nedocromil in topical therapy of seasonal allergic rhinoconjunctivitis The Deutsche Rhinitis-Studiengruppe. Arzneimittelforschung 48(9):924930

24. Baiardini I, Braido F, Tarantini F, Porcu A, Bonini S, Bousquet P, Zuberbier T, Demoly P, Canonica G (2008) ARIA suggested drugs for allergic rhinitis: what impact on quality of life? A GA2LEN review. Allergy 63(6):660-669 